\title{
Avaliação de não conformidades de próteses de quadril fabricadas com ligas de titânio e aço inox
}

\section{Evaluation of non-conformities of hip prostheses made of titanium alloys and stainless steel}

\author{
Ewerton de Oliveira Teotônio Bezerra ${ }^{1}$, José Jeferson da Silva Nascimento ${ }^{1}$, \\ Carlos Bruno Barreto Luna ${ }^{1}$, Crislene Rodrigues da Silva Morais ${ }^{1}$, \\ Karla Valéria Miranda de Campos ${ }^{1}$
}

\footnotetext{
${ }^{1}$ Unidade Acadêmica de Engenharia de Materiais, UAEMa/CCT/UFCG, Rua: Aprígio Veloso, 882, cep 58429-140, Campina Grande, PB. Emails: ewerton.teotonio@hotmail.com; brunobarretodemaufcg@hotmail.com
}

\section{RESUMO}

Um grande número de ligas metálicas apresenta comportamento satisfatório quando usadas na fabricação de implantes para próteses de quadril. Porém, as mesmas devem estar em conformidades com as normatizações, para assegurar sua qualidade por longos períodos e sem perder sua funcionalidade. Portanto, o presente trabalho tem como objetivo estudar as não conformidades de duas próteses de quadril, sendo uma de titânio e outra de aço inoxidável frente às normatizações. As próteses estudadas passaram por análise de difração de raios-x (DRX), fluorescência de raios-x, ensaio de tração e microscopia óptica (MO). As amostras para o ensaio de tração foram confeccionadas conforme a norma ASTM E 8M, bem como, as amostras do MO passou pelo procedimento metalográfico. Os resultados evidenciaram que algumas composições químicas apresentaram discordância em relação às normas. As análises de DRX mostraram picos de austenita e ausência de ferrita para o aço inoxidável, enquanto a liga de titânio apresenta uma fase alfa (HC) mais significativa que a fase beta (CCC). As ligas de aço inox e titânio apresentam limite de escoamento e resistência à tração que atendem as normas. Por outro lado, o módulo de elasticidade das ligas de titânio e aço inox, chega a ser dez vezes maior do que o módulo do osso humano. Portanto, o alto módulo de elasticidade das ligas, favorece problemas de reabsorção óssea. A microestrutura do aço inox é típica de uma matriz austenítica, enquanto a da liga de titânio apresenta microestruturas $\alpha+\beta$.

Palavras-chave: Biomateriais metálicos, aço inoxidável, liga de titânio, inconformidades.

\section{ABSTRACT}

A large number of metallic alloys has satisfactory behavior when used to manufacture implants for hip prostheses. However, they must be in conformity with standards, to ensure their quality for long periods without losing its functionality. Therefore, this paper aims to study the non-conformities in two hip prostheses, one of titanium and other stainless steel according to standards. The implants studied passed by $\mathrm{x}-$ ray diffraction (XRD), x-ray fluorescence, tensile test and optical microscopy (OM). Specimens for the tensile test were made according to ASTM E 8M, as well, MO samples passed by metallographic procedure. The results evidenced that some chemical compositions showed in relation to the standards. The XRD analysis showed peaks of austenite and absence of ferrite for the stainless steel, while the titanium alloy presents an alpha phase (HCP) more significant than the beta phase (BCC). The stainless steel alloys and titanium have yield strength and tensile strength that meet the standards. On the other hand, the elastic modulus of the titanium alloy and stainless steel, comes to be ten times greater than the human bone. Therefore, the high modulus of elasticity of the alloys, favors bone resorption problems. The stainless steel microstructure is typical of an austenitic matrix, while the titanium alloy presents $\alpha+\beta$ microstructure.

Keywords: Metallic biomaterials, stainless steel, titanium, unconformities. 


\section{INTRODUÇÃO}

Atualmente, o avanço tecnológico tem contribuído para o aumento da qualidade de vida, contudo, com o aumento da idade, tem-se necessidade de construir novos dispositivos que suprem com maior eficácia as necessidades físicas e biológicas humanas. Em virtude desse aumento na longevidade, algumas doenças como a osteoartrose, osteoporose, displasia do quadril, fraturas e sequelas de fraturas chamam a atenção para a utilização de dispositivos biomédicos que ofereçam mais qualidade de vida [1].

Os biomateriais metálicos geralmente são utilizados em grandes escalas na reposição de materiais rígidos do corpo, utilizados para a substituição de ossos, articulações e próteses ortopédicas, podendo também ser usados para aplicações cardiovasculares [2]. Neste contexto, a substituição de articulações (artroplastia) é um dos mais eficazes procedimentos cirúrgicos, fazendo com que as pesquisas de desenvolvimento de materiais para esta aplicação, sejam a que concentra maior atenção. A artroplastias total de quadril, joelho e ombro são, nesta ordem, os três procedimentos mais realizados. Porém, a artroplastia total de quadril, é a que tem maior repercussão entre os especialistas em ortopedia devido às demandas apresentadas por milhares de pessoas em todo mundo acometidas por artrite, osteoporose e ainda vítimas de acidentes [3-4].

A artroplastia de quadril ou simplesmente prótese de quadril é um procedimento cirúrgico que tem como objetivo substituir a articulação natural doente ou fraturada, por uma articulação artificial constituída por materiais não orgânicos chamados implantes protéticos. Porém, quando o desgaste já está instalado, a artroplastia total de quadril é a opção mais eficiente de tratamento, pois restabelece os movimentos da articulação, alivia a dor e permite a realização de atividades comprometidas pela destruição da articulação. As próteses para substituição total de quadril consistem basicamente de um componente femoral e um acetabular. A parte femoral é dividida em cabeça, pescoço e haste. A haste e o pescoço são geralmente fabricados de ligas metálicas de aço inoxidável ASTM F138, titânio ou cromo-cobalto, ao passo que a cabeça é confeccionada de liga de CoCr, alumina ou zircônia [5-6]. As ligas de cobalto-cromo, o titânio puro e as ligas de titânio, às quais são mais resistentes à corrosão, são utilizados principalmente na confecção de próteses permanentes. $\mathrm{O}$ titânio e suas ligas também têm a vantagem de possuir densidade e módulo de elasticidade relativamente baixa em relação aos outros biomateriais metálicos. Também é notório, o aço inoxidável, devido às suas propriedades mecânicas adequadas e razoável resistência à corrosão, além de boa usinabilidade e, principalmente, ao custo relativamente baixo [7]. Observa-se que um grande número de ligas metálicas apresenta comportamento satisfatório quando usados na fabricação de implantes.

GIODANI et al. [8] avaliaram comparativamente as microestruturas e as propriedades mecânicas, fadiga e corrosão do aço inoxidável austenítico ASTM F138 com a do aço inoxidável com alto nitrogênio de classificação ISO 5832-9. Os resultados evidenciaram que os dois aços têm estrutura austenítica, não sendo observado, em nenhum deles, a presença de ferrita. O aço ISO 5832-9 apresentou comportamentos mecânico e eletroquímico bastante superior ao aço ASTM F138. O melhor desempenho em corrosão do aço ISO 58329, quando comparado com o aço F 138, pode ser atribuído, principalmente, ao nitrogênio em solução sólida. A combinação de alta resistência mecânica e à corrosão localizada sugere que o aço ISO 5832-9 é um material muito promissor para a fabricação de implantes ortopédicos, podendo substituir o aço F 138, principalmente em aplicações mais severas de carregamento e tempos longos de permanência no interior do corpo humano.

Os implantes para aplicações ortopédicas permanentes precisam ter a sua qualidade assegurada, para atuar por longos períodos, sem perder sua funcionalidade, evitando problemas que possam causar danos à vida do paciente, bem como suportar elevados níveis de carregamento. Para isso, as ligas utilizadas nas fabricações dos implantes devem estar em conformidade com as especificações das normas técnicas [9]. Portanto, uma série de testes é exigida pelas agências reguladoras como a ANVISA (Agencia Nacional de Vigilância Sanitária), baseados em normas técnicas ISO (International Organization Standardization), ASTM (American Society For Testing And Materials From AISI) e DIN (Deutsches Institut für Normung), entre outras [10].

Neste contexto, o presente trabalho tem como objetivo avaliar não conformidades em duas próteses de quadril, sendo uma de aço inoxidável e outra de titânio frente às normatizações. Para isso, utilizou-se como referência as normas ASTM F 138 para o aço inoxidável e ASTM F 1108 para a liga de titânio. 


\section{MATERIAIS E MÉTODOS}

\subsection{Materiais}

Foram utilizadas duas amostras metálicas forjadas de próteses de quadril, sendo uma de aço inoxidável austenítico ASTM F 138-08 e outra de titânio Ti6Al4V. Nas duas amostras não foi possível à identificação de suas procedências, visto que não apresentava especificação do fabricante, lote e data de fabricação. Além disso, não foi divulgado o tempo de uso das próteses.

\subsection{Métodos}

Os implantes removidos foram limpos em ultra-som com acetona durante oito horas para remoção de material orgânico aderido à superfície do aço. O procedimento de limpeza foi conforme [11].

Os corpos de prova das duas amostras metálicas de próteses de quadril foram confeccionados no SENAI Odilon Ribeiro Coutinho em João Pessoa. As amostras foram usinadas com forma e dimensões que estão de acordo com as especificações definidas na norma ASTM E 8M. A Figura 1 mostra o modelo do corpo de prova confeccionado conforme a norma ASTM E 8M.

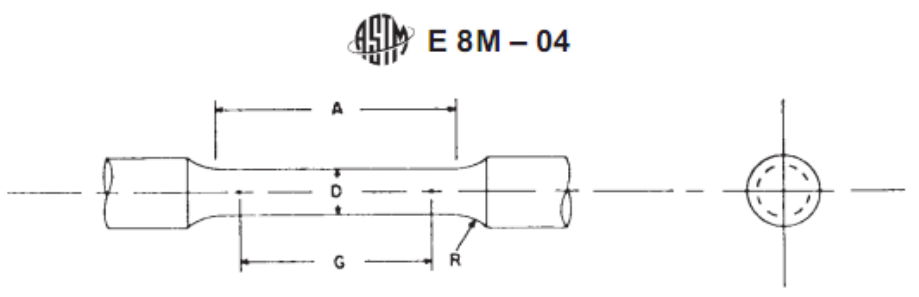

\begin{tabular}{|c|c|c|c|c|c|}
\hline \multicolumn{6}{|c|}{ Dimensions, mm } \\
\hline & Standa & & Size Specime & roportional To & dard \\
\hline & 12.5 & 9 & 6 & 4 & 2.5 \\
\hline G-Gage length & $62.5 \pm 0.1$ & $45.0 \pm 0.1$ & $30.0 \pm 0.1$ & $20.0 \pm 0.1$ & $12.5 \pm 0.1$ \\
\hline$D$-Diameter (Note 1) & $12.5 \pm 0.2$ & $9.0 \pm 0.1$ & $6.0 \pm 0.1$ & $4.0 \pm 0.1$ & $2.5 \pm 0.1$ \\
\hline$R-$ Radius of fillet, min & 10 & 8 & 6 & 4 & 2 \\
\hline A-Length of reduced section, $\min$ (Note 2) & 75 & 54 & 36 & 24 & 20 \\
\hline
\end{tabular}

Figura 1: Corpos de prova confeccionados a partir das próteses metálicas conforme a norma ASTM E 8M.

Os corpos de prova para a análise de microscopia ótica foram obtidas após alguns processos metalográficos, tais como: corte, embutimento, lixamento, polimento e ataque químico, sendo este último procedimento utilizando duas soluções. As amostras foram seccionadas nas direções longitudinais e transversais, em cortadora metalográfica e, em seguida, embutidas a frio em acrílico. O lixamento das amostras foi realizado em uma lixadeira politriz manual, com lixa comum de carbeto de silício (SiC), de granulometrias $120,220,320,400,600,800,1200$ e 2000. O processo foi intercalado por lavagem a cada mudança de lixa e secagem final com álcool etílico. $\mathrm{O}$ ataque químico foi realizado com solução aquosa contendo $15 \%$ de ácido clorídrico $(\mathrm{HCl})$ com $5 \%$ de ácido nítrico $\left(\mathrm{HNO}_{3}\right)$ para a liga de aço inoxidável, enquanto a liga de titânio foi atacada com uma solução aquosa de $10 \%$ de ácido fluorídrico com 5\% de ácido nítrico $\left(\mathrm{HNO}_{3}\right)$, por 60 segundos. Depois de atacadas, as amostras foram lavadas com detergente e água e, posteriormente, secas em ar quente.

\section{TÉCNICAS DE CARACTERIZAÇÃO}

As análises de difração de raios-x (DRX) foram obtidos em um aparelho XRD-600 Shimadzu, na faixa de $2 \theta$ $=20-90^{\circ}$, com um passo de $0,02^{\circ}$ e tempo de $1,0 \mathrm{~s}$, utilizando radiação de $\mathrm{K} \alpha$ de cobre como fonte de radiação monocromática. A identificação das fases presentes nas amostras foi realizada utilizando o banco de dados cristalográficos do ICDD (International Center for Diffraction Data). A composição química das amostras foi determinada através da técnica de fluorescência de raios-X em um equipamento EDX 720 da Shimadzu. As amostras foram extraídas da seção transversal submetidas a um polimento superficial, com espessura de $0,5 \mathrm{~mm}$, bem como o experimento foi realizada a temperatura ambiente.

Os ensaios de resistência à tração foram realizados em corpos de provas segundo a norma ASTM E $8 \mathrm{M}$ utilizando uma máquina de ensaio universal INSTROM 5582. Os ensaios foram realizados em temperatura ambiente, usando uma célula de carga de até $4900 \mathrm{~N}$ com uma taxa de tração de $1 \mathrm{~mm} / \mathrm{min}$. 
As micrografias obtidas por MO foram realizadas em um microscópio óptico, marca Olympus, modelo BX51M.

\section{RESULTADOS E DISCUSSÃO}

\subsection{Composição Química}

A Tabela 1 mostra os elementos presentes no aço inoxidável estudado, com suas respectivas percentagens em peso para cada elemento, bem como, o limite máximo permitido conforme a norma ASTM F138.

Tabela 1: Composições percentuais da liga de aço inoxidável estudada e porcentagem recomendada pela norma ASTM F138.

\begin{tabular}{lcc}
\hline \multicolumn{1}{c}{ Elementos } & $\begin{array}{c}\text { ASTM F 138 } \\
(\mathbf{\%} \mathbf{~ p / p )}\end{array}$ & $\begin{array}{c}\text { Aço Inox Estudado } \\
(\mathbf{\%} \mathbf{p} / \mathbf{p})\end{array}$ \\
\hline Carbono (C) & 0,030 máx. & 0,01 \\
Manganês (Mn) & 2,00 máx. & 1,76 \\
Fósforo (P) & 0,025 máx. & 0,10 \\
Enxofre (S) & 0,010 máx. & 0,20 \\
Silício (Si) & 0,75 máx. & 0,50 \\
Cromo (Cr) & $17,00-19,00$ & 17,35 \\
Níquel (Ni) & $13,00-15,00$ & 13,44 \\
Molibdênio (Mo) & $2,25-3,00$ & 2,83 \\
Nitrogênio (N) & 0,10 máx. & Não foi identificado \\
Cobre (Cu) & 0,50 máx. & Não foi identificado \\
Ferro (Fe) & Balanço & 61,36 \\
Alumínio (Al) & Não possui & 0,72 \\
Césio (Cs) & Não possui & 0,13 \\
Cloro (Cl) & Não possui & 0,09 \\
\hline
\end{tabular}

A resistência à corrosão é uma das características fundamentais para a seleção de uma liga metálica utilizada na fabricação de um produto implantável, pois os fluídos biológicos presente no corpo humano possuem alto poder corrosivo. Conforme se observa na Tabela 1, nota-se a presença dos elementos cromo e molibdênio, respectivamente, com teores de 17,35 e 2,83\%. Os teores desses elementos estão conforme as especificações da norma ASTM F 138 e, portanto, garantindo estabilidade contra corrosão por pites que eventualmente possa ocorrer na prótese de quadril em contato com os fluidos corporais. Conforme reportado na literatura [12], a fórmula que fornece uma medida da relação entre a porcentagem (\%) em peso do conteúdo de $\mathrm{Cr}$ e Mo para que se espere a resistência à corrosão por Pite é dada pela Equação 1. A mesma pode ser utilizada quando a liga metálica é submetida a fluidos corporais [13].

$$
\% \mathrm{Cr}+3,3 \times \% \mathrm{Mo} \geq 26,0
$$

A resistência à corrosão para a liga de aço inox estudada foi obtido substituindo os valores percentuais de cromo e molibdênio na Equação 1 . O valor obtido foi de $26,7 \%$ em peso, que é comparativamente superior ao valor especificado na restrição da equação 1, sugerindo-se que esta liga apresente boa resistência à corrosão por pite.

Conforme [12], a boa resistência à corrosão dos aços inoxidáveis utilizados em próteses de quadril, se deve, principalmente, ao seu elevado teor de cromo. O cromo na superfície do aço reage quimicamente com o oxigênio, formando uma fina camada de óxido de cromo sobre o metal, denominada camada de passivação, que confere proteção contra agentes corrosivos. Em próteses implantadas, a camada de passivação protege o metal contra o ataque corrosivo de íons cloreto, presentes no sangue e nos demais fluídos biológicos. Além disso, durante o processo de fabricação de um aço inoxidável, geralmente, ocorre adição de molibdênio, em 
teores acima de $2 \%$, o que permite a formação de uma camada de passivação mais resistente a meios salinos agressivos.

Quanto às composições percentuais dos elementos fósforo e enxofre no aço, apresentam valores bem superiores ao aço ASTM F138, podendo comprometer suas propriedades mecânicas. A presença dos elementos fósforo e enxofre em ligas de aços inoxidáveis, geralmente, contribuem para formação de fases frágeis (inclusões não metálicas) durante o processo de fabricação do aço, reduzindo a homogeneidade do metal [13]. Isso pode prejudicar a vida útil da prótese de quadril, bem como fraturar de forma frágil durante o deslocamento do paciente que passou pelo implante. Além disso, pequenas concentrações de fósforo proporciona uma melhor ductibilidade, principalmente em implantes cirúrgicos que são submetidos a carregamentos a frio [14-15].

Os elementos $\mathrm{Al}, \mathrm{Cs}$ e $\mathrm{Cl}$ foram identificados no aço inoxidável em estudo e, portanto, estando em desacordo com a norma ASTM F138. A presença destes três elementos pode vir a gerar preocupações, pois podem comprometer a qualidade da prótese de quadril. O alumínio nas estruturas de aços atua como desoxidante, desgaseificante, refinador de grão e, principalmente, para acalmar os aços de baixo carbono, controlando o tamanho de grão da austenita. Embora tenha como objetivo o controle da fase austenítica na estrutura do aço, o uso desse elemento é inadequado para aços com fins ortopédicos. O elemento césio não é considerado um elemento de liga em aços, e não há relatos na literatura que trate sobre a existência e/ou influência deste elemento sobre ligas metálicas. Portanto, nesta pesquisa esse elemento é considerado um contaminante. $\mathrm{O}$ cloro que se encontra presente na estrutura do aço, provavelmente ocasionará desgaste corrosivo acelerado do biomaterial e, portanto, reduzindo a vida útil. De certa forma, a presença destes três elementos é preocupante, pois não sabe-se os efeitos no organismo, mesmos estes estando em baixo teores. Tais elementos fora da especificação da norma, provavelmente pode gerar alguma liberação de íns indesejáveis no organismo, bem como causar mudanças na histologia do tecido local, tanto por efeitos tóxicos diretos quanto por uma hipersensibilidade local.

Os elementos cobre e nitrogênio não foram detectados nos resultados. Enquanto, o teor de carbono esta dentro da norma. Os teores de carbono mais baixos que os valores máximos estabelecidos pelas normas, indicam que dificilmente haverá a formação no contorno de grão do composto $\mathrm{Cr}_{23} \mathrm{O}_{6}$, responsável pela perda de cromo nessa região, com o empobrecimento desse elemento e a perda das características de resistência à corrosão oferecida pelo cromo [16]. Na peça estudada de aço inoxidável, o teor de níquel mostrado na Tabela 1, apresenta-se na faixa ideal. Já o teor de silício está dentro da faixa especificada pela norma e, consequentemente, garantido melhora nas propriedades do aço inoxidável.

Em última análise, o aço inoxidável estudado neste trabalho apresentou composição química fora do que foi estabelecido pela norma de referência para alguns elementos, o que compromete a qualidade do produto.

A Tabela 2 apresenta as composições das ligas de titânio, Ti6Al4V especificada pela norma ASTM F 1108 e da liga de titânio utilizada em próteses de quadril.

Tabela 2: Composições percentuais da liga Ti6A14V conforme norma ASTM F 1108 e da liga de titânio estudada.

\begin{tabular}{|c|c|c|}
\hline Elementos & $\begin{array}{c}\text { Ti6Al4V (F } 1108) \\
(\% \mathrm{p} / \mathrm{p})\end{array}$ & $\begin{array}{c}\text { Liga de Titânio } \\
\text { Estudado (\% p/p) }\end{array}$ \\
\hline Nitrogênio (N) & 0,05 máx. & Não foi identificado \\
\hline Carbono (C) & 0,10 máx. & 0,04 \\
\hline Hidrogênio (H) & 0,012 máx. & Não foi identificado \\
\hline Ferro $(\mathrm{Fe})$ & 0,30 máx. & 0,56 \\
\hline Oxigênio $(\mathrm{O})$ & 0,20 máx. & 0,17 \\
\hline Alumínio (Al) & $5,5-6,75$ & 3,78 \\
\hline Vanádio (Va) & $3,5-4,5$ & 3,76 \\
\hline Titânio (Ti) & Balanço & 76,22 \\
\hline Bário (Ba) & Não possui & 2,44 \\
\hline Potássio (K) & Não possui & 0,39 \\
\hline
\end{tabular}




\begin{tabular}{lll} 
Enxofre $(\mathrm{S})$ & Não possui & 0,32 \\
Sílicio $(\mathrm{Si})$ & Não possui & 0,28 \\
Níquel $(\mathrm{Ni})$ & Não possui & 0,07 \\
Cobre $(\mathrm{Cu})$ & Não possui & 0,05 \\
Manganês $(\mathrm{Mn})$ & Não possui & 0,05 \\
Cálcio $(\mathrm{Ca})$ & Não possui & 0,05 \\
Zinco $(\mathrm{Zn})$ & Não possui & 0,04 \\
\hline
\end{tabular}

Conforme verifica-se na Tabela 2, os resultados da liga de titânio estudada, apresentou dezessete elementos. Doze destes elementos não estão de acordo com a composição da liga de titânio ASTM F1108. Dentre esses elementos, silício, níquel, cobre e manganês são elementos de ligas estabilizadores da fase- $\beta$, ou seja, são elementos que mantém a liga com estrutura CCC em temperaturas mais baixas [17].

$\mathrm{O}$ níquel é utilizado comumente em ortodontia, principalmente em ligas especiais de NiTi denominadas de nitinol, apresentando propriedades de superelasticidade e o efeito de memória de forma, além de ser biocompatível [18-19]. Entretanto, não foram encontrados estudos que relacionem o uso deste tipo de liga à artroplastia, bem como, não é especificado a presença do elemento níquel compondo a liga Ti6Al4V conforme a norma da ASTM F1108.

Também foram identificados impurezas de bário, potássio, enxofre, cálcio e zinco. Observa-se na Tabela 2, que o elemento bário possui o quarto maior percentual da liga. Ao certo, não é possível afirmar a origem que possa ter ocasionado à presença do bário nessa liga, mas, estudos sobre ligas de titânio, associam este elemento aos solventes que são utilizados na limpeza da superfície das próteses [20]. Portanto, a presença deste elemento na liga é inadequada, estando totalmente em discordância com a norma ASTM F 1108.

Traços de potássio, enxofre, cálcio e zinco totalizam $0,80 \%$, provavelmente originados a partir da confecção, limpeza da superfície e dos processos de esterilização dos implantes, ou seja, advindos de falhas no processo de produção. Nos estudos de HELLSING [21] evidenciaram as diferentes origens destes elementos em superfícies de ligas de titânio. O potássio é associado aos lubrificantes e solventes usados na produção e esterilização dos implantes. A presença de enxofre em implantes é provavelmente originada como resultado do uso de solventes na limpeza da superfície do metal. A presença de cálcio possivelmente tem procedência de soluções utilizadas na limpeza dos implantes, podendo também ter como origem, a esterilização a vapor.

Enfim, provavelmente os diferentes modos de preparação dos implantes é um dos fatores responsáveis pelo aparecimento de contaminantes na superfície dessas ligas. Além disso, os contaminantes podem interferir na osseointegração, dificultando ou até mesmo impedindo a mesma [22].

Outro elemento encontrado com composição superior ao estabelecido pela norma ASTM F1108 é o ferro. Na liga de titânio, esse elemento atua como um estabilizador da fase- $\beta$, melhorando suas propriedades mecânicas e sua resistência à corrosão. Este alto conteúdo de ferro na liga, possivelmente seja devido aos processos mecânicos que a haste metálica possa ter sido submetida [23].

Diante do que foi apresentado, a composição química da liga avaliada, diverge do que foi estabelecido pela ASTM F1108 e, portanto, comprometendo a qualidade deste material.

\subsection{Difração de Raios-X (DRX)}

A técnica de difração de raios-x foi utilizada como ferramenta, para verificar se existe a presença de ferrita $\alpha$ na prótese de quadril de aço inoxidável. A Figura 3 mostra o difratograma do aço inoxidável utilizado na fabricação de próteses de quadril. 


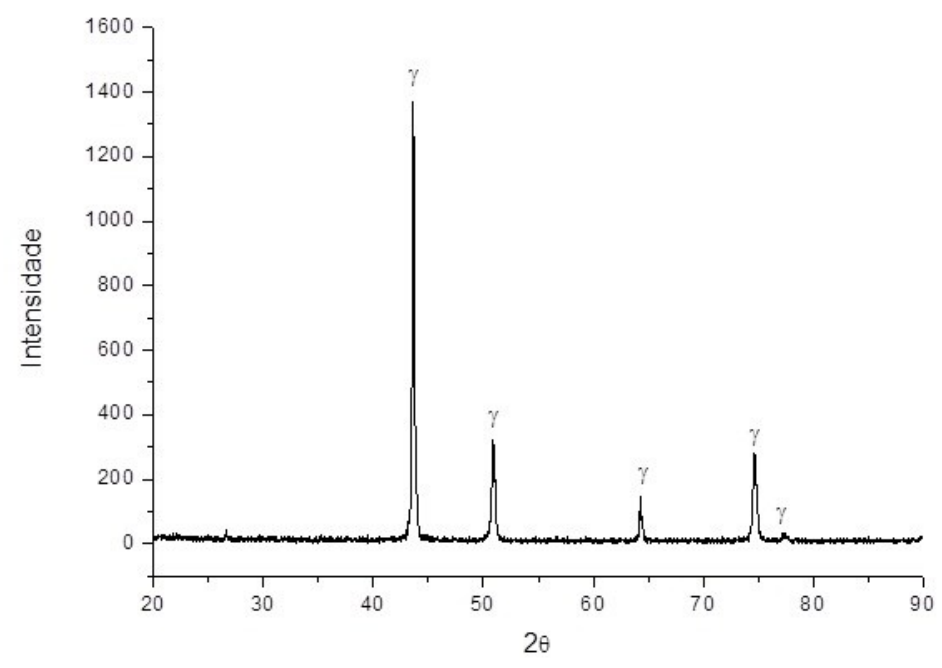

Figura 3: Difratograma da liga de aço inoxidável utilizada em prótese de quadril.

Conforme se observa na Figura 3, os picos localizados em $43,6^{\circ} ; 50,9^{\circ}$ e $74,7^{\circ}$ compõem os principais picos da fase austenítica. No difratograma da Figura 3 não foi identificados picos relativos à fase ferrítica, característica desejável para os aços inoxidáveis austeníticos utilizados em implantes ortopédicos por reduzir à suscetibilidade à corrosão e, promover, boas propriedades mecânicas, em especial à resistência à fadiga, bem como evitando a permeabilidade magnética do aço implantado. Portanto, os resultados indicam a presença de apenas uma matriz austenítica, contendo boa cristalinidade, evidenciado por picos estreitos e bem definido.

A Figura 4 apresenta o difratograma da liga de titânio estudada. Os picos de difração presentes neste diagrama são todos identificados como sendo oriundos das reflexões dos planos cristalográficos das fases $\alpha \mathrm{e}$ $\beta$.

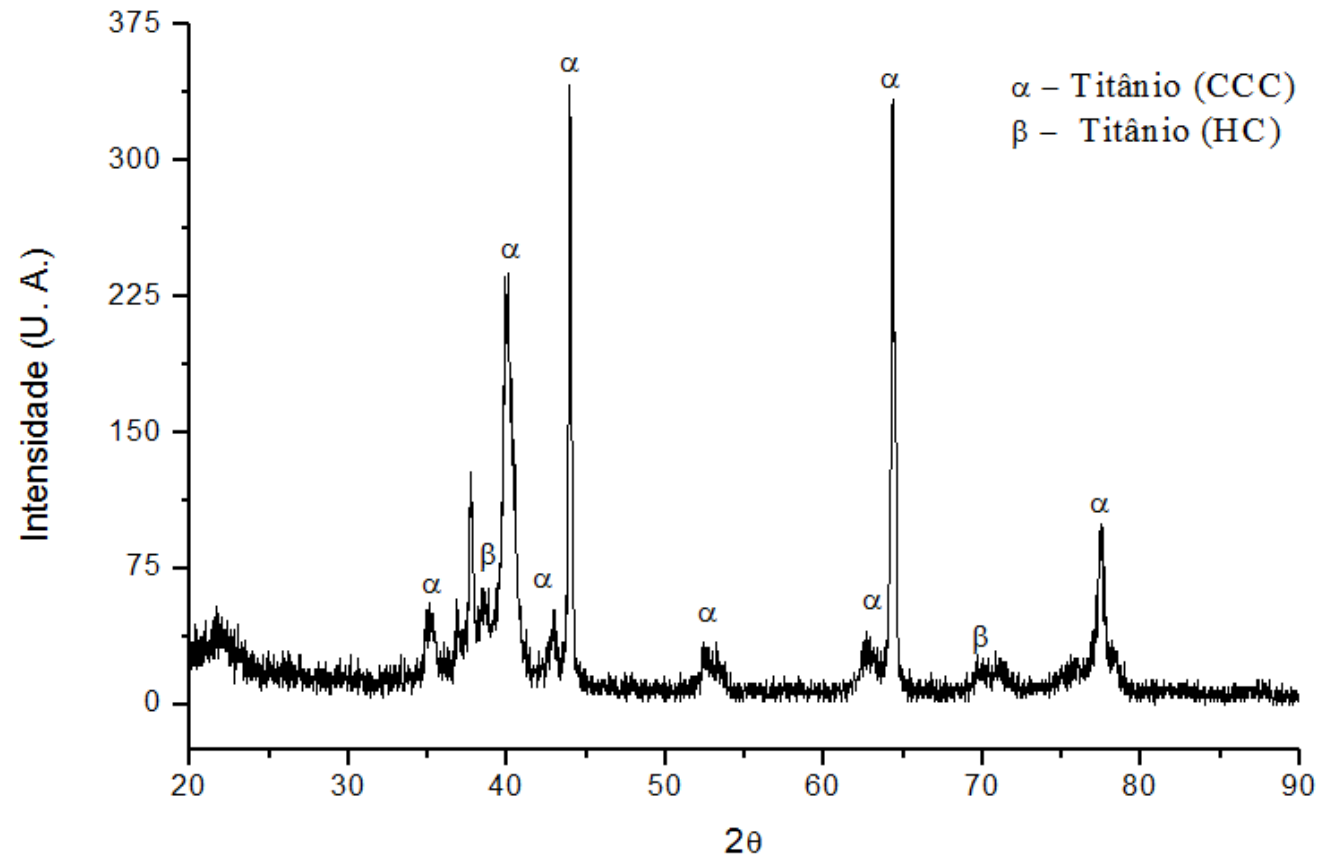

Figura 4: Difratograma da liga de titânio utilizada em prótese de quadril. 
Conforme a Figura 4, os três principais picos foram: $2 \theta=39,9^{\circ}, 2 \theta=77,4^{\circ}$ e $2 \theta=35,2^{\circ}$, que correspondem aos planos (101), (100) e (201), associados a microestrutura $\alpha$ de estrutura hexagonal. A análise do difratograma revela também que a identificação da fase $\beta$ é mais complexa que a identificação da

fase $\alpha$. Observa-se que apenas dois picos da fase $\beta$ foram identificados no difratograma, sendo posicionados em $2 \theta=38,6^{\circ}, 2 \theta=69,9^{\circ}$, correspondendo aos planos (110) e (211), respectivamente. Conforme LI et al. [24] relataram que a dificuldade em identificar, por difratometria de raios-x, a presença de fase $\beta$ nas ligas de titânio quando a fase $\alpha$ está presente, é devido ao fato do plano de reflexão mais intenso da fase $\beta$ (110) ter posição coincidente a um plano de reflexão da fase $\alpha(002)$ e, por isso, mascarando o resultado.

Pela analise do difratograma da Figura 4 e baseando-se nas intensidades dos picos, podemos predizer quantitativamente que a presença da fase alfa (HC) é mais significativa que a fase beta (CCC), assim, evidenciando uma liga Ti6AL4V $(\alpha+\beta)$. Conforme ALEIXO et al. [25], para as ligas de Ti6AL4V $(\alpha+\beta)$, o módulo de elasticidade das mesma é muito elevado em comparação com os ossos corticais. Portanto, pode ocorrer a transferência inadequada de esforços entre a prótese e os ossos da região e, consequentemente, pode levar a rejeição e perda do implante. Essa previsão de alto módulo de elasticidade é confirmada pelos resultados de tração.

Conforme se observa na Tabela 2, ficou evidenciado que $2,44 \%$ é de bário. Porém, diante dos resultados de difração da liga de titânio, não foram identificados picos cristalinos associados à fase cristalina do bário, descartando a possibilidade deste elemento está inserido como um elemento substitucional nesta liga.

\subsection{Ensaio de Tração}

A resistência mecânica das ligas de aço inox e titânio foram avaliados de acordo com as normas da ASTM, sendo a F138 para liga de aço inoxidável e a F1108 para liga de titânio. As normas estabelecem $860 \mathrm{MPa}$ como valor mínimo do limite de resistência à tração.

A Figura 5 mostra as curvas tensão-deformação obtida no ensaio de tração para os dois materiais estudados.
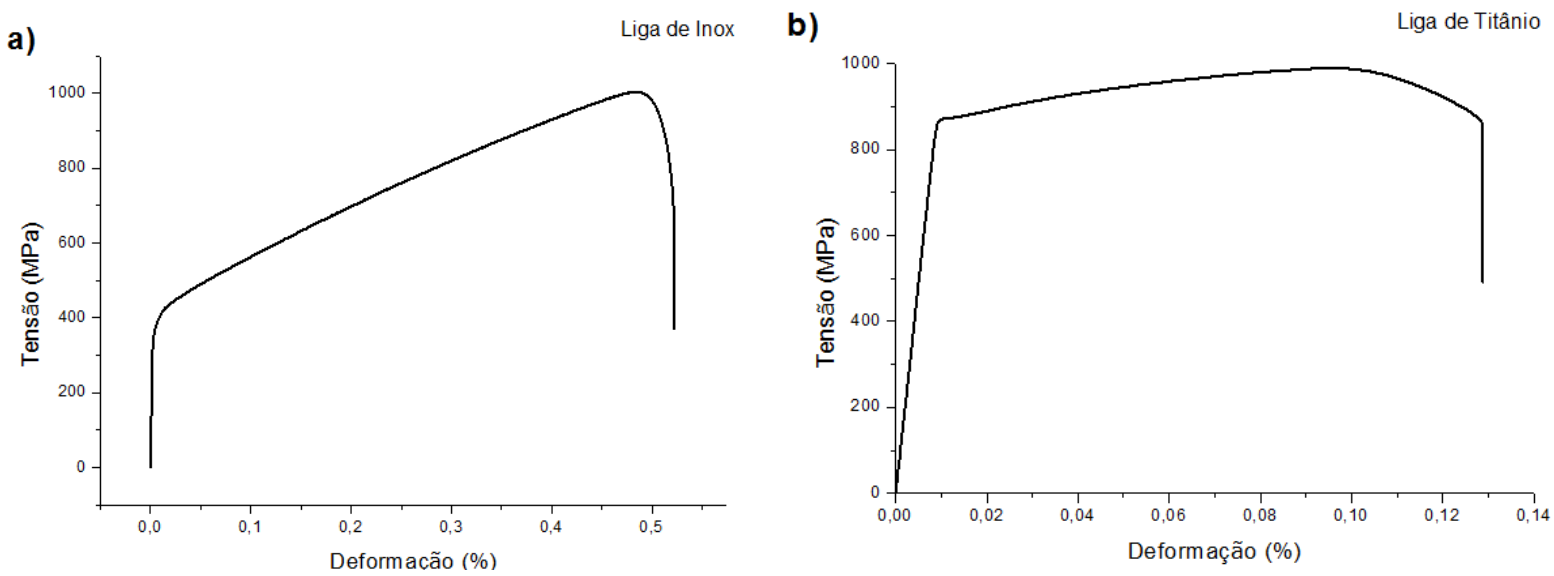

Figura 5: Curvas tensão-deformação obtidas no ensaio de tração para: a) aço inox; b) liga de titânio.

Conforme se observa na Figura 5, as ligas de aço inox e titânio apresentam limites de resistência à tração que atendem ao estabelecido pelas normas ASTM F138 e F1108, respectivamente. Observa-se que os limites de resistência à tração destas ligas, apresentam valores superiores ao estabelecido pelas normas ASTM. Os resultados evidenciam que as hastes metálicas constituídas de ligas de titânio e aço inoxidável, apresentam resistências mecânicas adequadas para serem aplicadas em próteses de quadril. Observa-se na Figura $5 \mathrm{~b}$ que a ductibilidade da liga de titânio é, sensivelmente menor que a do aço inox (Figura 5a). Porém, é importante destacar que para fins de projeto, a tensão limite de escoamento é o parâmetro utilizado. A norma ASTM F 138 recomenda um limite de escoamento mínimo de $690 \mathrm{MPa}$, enquanto a norma ASTM F 1108 sugere um mínimo de $758 \mathrm{MPa}$. Portanto, as duas próteses em estudo estão conforme ao mínimo exigido. 
O módulo de elasticidade das ligas de titânio (95 GPa) e aço inox (179 GPa), chegam a ficar na faixa de 6 a 10 vezes maior do que o módulo do osso humano (11 -17 GPa). Estes valores evidenciam a possibilidade de haver reabsorção óssea e, consequentemente, afrouxamento da prótese implantada, podendo favorecer a um desequilíbrio de forças no quadril e o resultado final pode ser perda óssea na região do implante. Neste caso, a substituição da prótese poderá ser a única solução. No entanto, o módulo de elasticidade da haste metálica da liga de titânio é bem menor do que a do aço inox, possibilitando maior tempo para reabsorção óssea, e como essa liga possui melhor resistência à corrosão que os aços inox, implica em uma prótese com maior confiabilidade e maior vida útil que as constituintes por aço inox [26-27].

BANASZKIEWICZ [28] reportou que o módulo de elasticidade do osso é mais flexível do que a liga de titânio. Quando tensões maiores são aplicadas a uma prótese sobre o implante, a liga de titânio tem uma deformação menor comparada com o osso. A diferença entre os dois materiais pode criar situações de microdeformações de sobrecarga patológica e, portanto, causar a perda do implante. Quando as tensões aplicadas ao implante são baixas, a diferença de micro-deformação entre a liga e o osso é minimizada, permanecendo em sua zona de adaptação, mantendo a capacidade de carga do osso na interface.

É importante saber que a cirurgia de um material com maior rigidez no interior do osso, pode causar a blindagem (Stress Shilding) e, portanto, ocasionar a remodelação óssea adaptativa. No geral, se o módulo de elasticidade do implante for muito maior do que o do osso, o implante vai assumir a carga e o osso circundante começará a morrer. Isto causará o afrouxamento do implante, podendo levar à sua inutilização. Por isso, a estabilidade e sobrevivência dos implantes irão depender, em grande parte, da resistência destes materiais e como os esforços serão transferidos da haste ao manto de cimento e/ou ao tecido ósseo adjacente [29].

\subsection{Microscopia Óptica (MO)}

A Figura 6 apresenta as micrografias obtidas por microscopia ótica das ligas de aço inoxidável e de titânio respectivamente. As imagens foram analisadas com um aumento de 200x.
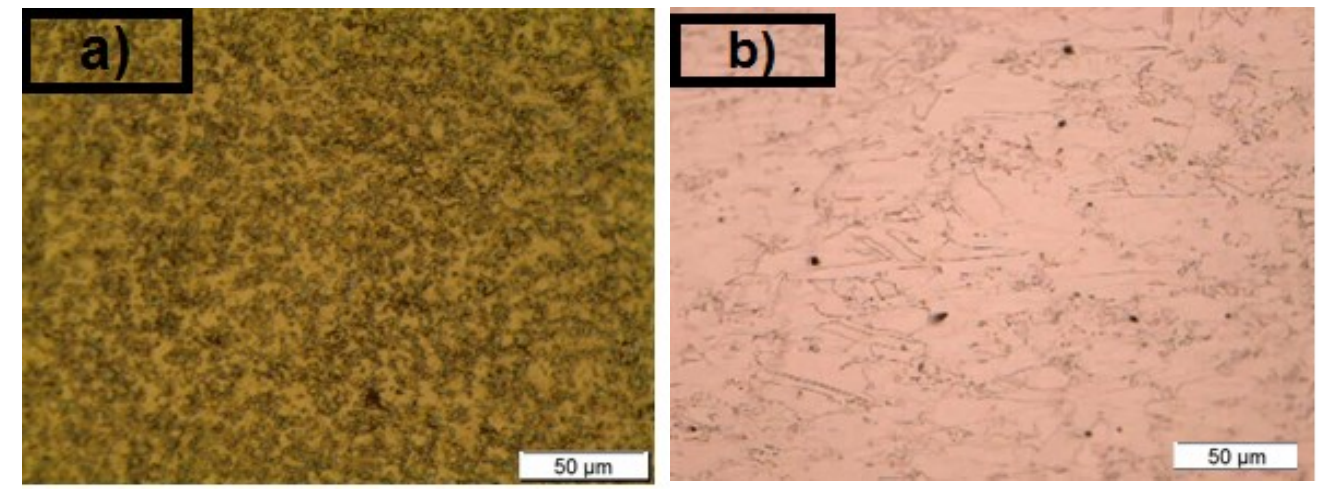

Figura 6: Micrografias óticas das ligas de: a) titânio; b) aço inoxidável ambas em escala de aumento de 200x.

A Figura 6a mostra a microestrutura da prótese de quadril utilizando ligas de titânio. Observa-se uma microestrutura marcada pela presença de duas fases. As regiões claras evidenciam uma matriz constituída de microestruturas $\alpha$, enquanto as partículas escuras revelam a presença da fase $\beta$.

A Figura 6 b evidencia a microestrutura da prótese de quadril utilizando aço inoxidável. A micrografia revela uma morfologia característica de uma matriz austenítica. É possível distinguir na imagem, que não há presença de microestruturas ferrítica. Estas características são desejáveis para os aços inoxidáveis austeníticos utilizados para implantes ortopédicos, por reduzirem à suscetibilidade à corrosão e promover boas propriedades mecânicas, em especial à resistência à fadiga.

O tamanho dos grãos em uma liga metálica influência as suas propriedades mecânicas, sendo que um material com granulação fina é mais duro e mais resistente do que um material que possui granulação grosseira, uma vez que o primeiro possui uma maior área total de contornos de grãos. Conforme foi observado nas discussões as propriedades atendem ao mínimo exigido pelas normas, o que sugere que as duas próteses em estudo apresente grão de tamanho adequando. 


\section{CONCLUSÕES}

O desenvolvimento de dispositivos e mecanismos que possam promover a melhoria da qualidade de vida das pessoas foi e continua sendo a grande motivação dos estudos relacionados com a área de saúde, em especial, ao desenvolvimento de biomateriais. Para se realizar implantes de biomateriais no corpo humano é necessário que esteja em conformidade com as normas de especificações. Porém, o que se observou no presente trabalho, foi que as ligas estudadas apresentam não conformidades de acordo com as normas, em relação à composição química, bem como valores elevados do modulo de elasticidade, o que pode levar a possíveis problemas de reabsorção óssea. A liga de aço inox apresentou composições percentuais dos elementos fósforo e enxofre bem superiores ao recomendado pela norma ASTM F 138, além disso, os elementos Al, Cs e $\mathrm{Cl}$ foram identificados no aço inoxidável, sendo que os mesmos não estão presentes na norma ASTM F 138. Já a liga de titânio apresentou impurezas de bário, potássio, enxofre, cálcio, zinco e níquel, sendo que nenhum é indicado conforme a norma ASTM F 1108. Já em relação ao módulo de elasticidade, foi encontrado altos valores para as próteses de quadril quando comparado ao módulo do osso. Sendo assim, o contato da prótese com os tecidos podem intensificar a reabsorção óssea, favorecendo fatores como liberação iônica provocada por excesso de atrito entre amostra e tecidos vivos. Portanto, existe necessidade de encontrar materiais metálicos com características físico-químicas mais apropriadas a implantes ortopédicos, o que pode impulsionar o desenvolvimento de várias composições de ligas, cujas propriedades minimizem as falhas de natureza fisiológica, mecânica e química.

\section{AGRADECIMENTOS}

Os autores agradecem a CAPES (Coordenação de Aperfeiçoamento de Pessoal de Nível Superior) pela concessão da bolsa de estudo, bem como, a UFCG pela infraestrutura para realização da pesquisa.

\section{BIBLIOGRAFIA}

[1] KURODA, P. A. B., CORREA, D. R. N., GRANDINI, C. R., “ Análise da microestrutura e microdureza da liga Ti-15Zr-5Mo para ser utilizada como um biomaterial”, In: Congresso Latino Americano de órgãos Artificiais e Biomateriais, pp. 1-9, Natal, Agosto, 2012.

[2] NASAB, M.B., HASSAN, M.R., "Metallic biomaterials of knee and hip - A review", Trends Biomaterials Artificial Organs, v. 24, pp. 69-82, 2010.

[3] RODRIGES, L. B., “Aplicações de biomateriais em ortopedia”, Estudos Tecnológicos em Engenharia, v. 9, pp. 63-76, 2013.

[4] PIRES, A. L. R., BIERHALZ, A. C. K., MORAES, A. M. "Biomateriais: tipos, aplicações e mercado". Química Nova, v. 38, pp. 957-971, 2015.

[5] SCHWARTSMANN, C. R., BOSCHIN, L. C., GONÇALVES, R. Z., et al., “ Novas superfícies em artroplastia total do quadril”, Revista Brasileira de Ortopedia, v. 47, pp. 154-159, 2012.

[6] KEENER, J.D, CAllaghan, J.J,, D.D, PEDERSON, D.R, SUlliVAN, P.M, JOHNSTON, R.C. "Twenty-five-year results after Charnley total hip arthroplasty in patients less than fifty years old: a concise follow-up of a previous report”, Journal of Bone Join Surgery, v. 85, pp. 1066-1072, 2003.

[7] OLIVEIRA, F. S., Caracterização e propriedades mecânicas de próteses para quadril, Dissertação de M.Sc., CCT/IME, Río de Janeiro, RJ, Brasil, 2013.

[8] GIORDANI, E.J., FERREIRA, I., BALANCIN, O., "Propriedades mecânicas e de corrosão de dois aços inoxidáveis austeníticos utilizados na fabricação de implantes ortopédicos", Revista Escola de Minas, v.60, p.55-62, 2007.

[9] GOTMAN, I., "Characteristics of metals used in implants”, Journal of Endurology, v.11, n.6, pp.383-389, 1997.

[10] ALVES, H. A., Desenvolvimento de um sistema de blindagem com lubrificação em próteses de quadril modular, Dissertação de M.Sc., CCT/Univap, São José dos Campos, SP, Brasil, 2008.

[11] SILVA, E. F., OLIVEIRA, L. F. C., “Caracterização química e metalográfica dos aços inoxidáveus de implantes removidos de pacientes”, Acta Ortopédica Brasileira, v. 19, pp. 280-285, 2011.

[12] DISEGI, J. A., ESCHBACH, L., "Stainless steel in bone surgery", International Journal of the Care of the Injured, v. 31, pp. 2-6, 2000.

[13] SILVA, E. F., OLIVEIRA, L. F. C. "Avaliação da resistência à corrosão de implantes em aços inoxidáveis ISO 5832-9 e F138 removidos de pacientes”, Química Nova, v. 35, pp. 59-65, 2012. 
[12] PEZZOTTI, G., YAMAMOTO, K., "Artificial hip joints: The biomaterials challenge", Journal of the Mechanical Behavior of Biomedical Materials, v. 31, pp. 3-20, 2014.

[13] GEETHA, M., SINGH, A. H., ASOKAMANI, R., et al., "Based biomaterials the ultimate choice for orthopaedic implantes - a review", Progress in Materials Science, v. 54, pp. 397-425, 2009.

[14] TABATA, Y., "Biomaterial technology for tissue engineering applications", Journal of the Royal Society interface, v. 6, pp. 311-324, 2009.

[15] CHIAVERINI, V., Aços e ferros fundidos, 7 ed., São Paulo, ABM, 2008.

[16] SILVA, E. F., OLIVEIRA, L. F. C. "Caracterização química e metalográfica dos aços inoxidáveis de implantes removidos de pacientes”, Acta Ortopédica Brasileira, v. 19, pp. 280-285, 2011.

[17] VILLARINHO, D. J., ROESE, P. B., FERREIRA, C., SCHAEFFER, L. "Caracterização parcial de liga Nitinol atuador através de pontos críticos de transformação de fases utilizando calorimetria diferencial de varredura", Estudos Tecnológicos, v. 6, pp. 01-10, 2010.

[18] VECHIETTI, F. A., PERES, R. S., MARTINS, V., MOZETIC, H., CORRÊA, F. J., SCHAFFER, L. "Tratamento térmico em stents de nitinol submetidos a ensaios de corrosão", Revista Ciência e Tecnologia, v. 15, pp. 02-07, 2012.

[19] SILVA, N. J., ARAÚJO, C. J., GONZALEZ, C. H., GRASSI, E. N. D., OLIVEIRA, C. A. N. "Estudo comparativo das propriedades dinâmicas de uma liga NiTi com memória de forma e materiais estruturais clássicos", Matéria (Rio J.), v. 16, pp. 830-835, 2011.

[20] ARONSSON, B. O., LAUSMAA, J., KASEMO, B. "Glow discharge plasma treatment for surface cleaning and modification of metallic biomaterials", Journal of Biomedical Materials Research, v. 35, pp. 49-73, 2007.

[21] HELLSING, M., "Comparative surface analysis of four dental implant systems", Journal of the Dental Association of South Africa, v. 52, pp. 399-402, 1997.

[22] JÚNIOR, C. A. R. F. T., SENDYK, W. R., MATOS, A. B., SANSIVIERO, A. "Contaminação química superficial de implantes osseointegrados: estágio atual”, Revista Instituto de Ciência e Saúde, v. 23, pp. 139$143,2005$.

[23] LÜTJERING, G., "Influence of processing on microstructure and mechanical properties of $(\alpha+\beta)$ titanium alloys", Materials Science and Engineering A, v. 243, pp. 32- 45, 1998.

[24] LI, Y., YANG, C., ZHAO, H., et al., "New developments of Ti-based alloys for biomedical applications", Materials, v. 7, n. 3, pp. 1709-1800, 2014

[25] ALEIXO, G. T., BUTTON, S. T., CARAM, R., "Forjamento de hastes de próteses femorais em ligas de titânio tipo ß", In: Congresso Brasileiro de Engenharia e Ciência dos Materiais, pp. 4311-4318, Foz do Iguaçu, Novembro, 2006.

[26] CALLISTER, W. D. J., "Ciência e engenharia de materiais: uma introdução", 5 ed., Rio de Janeiro, LTC, 2002.

[27] SANADA, J. T., Avaliação da resistência e módulo de elasticidade de osso mineralizado e desmineralizado pelos testes de microtração, Dissertação de M.Sc., CCT/IME, Bauru, SP, Brasil, 2007.

[28] BANASZKIEWICZ, P. A., "Metallic wear in failed titanium-alloy total hip replacements: A histological and quantitative analysis", Classic Paper in Orthopaedics, v. 2, pp. 97-100, 2013.

[29] DIESEGI, J.A., ESCHBACH, L., "Sainless steel in bone surgery", Revista Injury-international journal of the care of the injured, v. 31, pp. 2-6, 2000. 